\title{
Mechanical Behavior of Anisotropic Composite Materials as Micropolar Continua
}

\author{
Nicholas Fantuzzi ${ }^{1}$, Patrizia Trovalusci ${ }^{2 \star}$ and Snehith Dharasura ${ }^{1}$ \\ ${ }^{1}$ Department of Civil, Chemical, Environmental, and Materials Engineering, University of Bologna, Bologna, Italy, ${ }^{2}$ Department \\ of Structural and Geotechnical Engineering, Sapienza University of Rome, Rome, Italy
}

The macroscopic behavior of materials with anisotropic microstructure described as micropolar continua is investigated in the present work. Micropolar continua are characterized by a higher number of kinematical and dynamical descriptors than classical continua and related stress and strain measures, namely the micro-rotation gradient (curvature) and the relative rotation with their work conjugated counterparts, the micro-couple, and the skew-symmetric part of the stress, respectively. The presence of such enriched strain and stress fields can be detected especially when concentrated forces and/or geometric discontinuities are present. The effectiveness of the micropolar model to represent the mechanical behavior of materials made of particles of prominent

OPEN ACCESS

Edited by:

Chiara Daraio,

California Institute of Technology,

United States

Reviewed by:

Francesco Dal Corso,

University of Trento, Italy

Cesare Davini,

International Centre for Mechanical

Sciences, Italy

*Correspondence:

Patrizia Trovalusci

patrizia.trovalusci@uniroma1.it

Specialty section:

This article was submitted to

Mechanics of Materials,

a section of the journal

Frontiers in Materials

Received: 08 December 2018

Accepted: 25 March 2019

Published: 18 April 2019

Citation:

Fantuzzi N, Trovalusci P and

Dharasura S (2019) Mechanical

Behavior of Anisotropic Composite Materials as Micropolar Continua.

Front. Mater. 6:59.

doi: 10.3389/fmats.2019.00059 size has been widely proved in the literature, in this paper we focus on the capability of this model to grossly capture the behavior of anisotropic solids under concentrated loads for which the relative strain, that is a peculiar strain measure of the micropolar model, can have a salient role. The effect of material anisotropy in the load diffusion has been investigated and highlighted with the aid of numerical parametric analyses, performed for two dimensional bodies with increasing degrees of anisotropy using a finite element approach specifically conceived for micropolar media with quadratic elements implemented within Comsol Multiphysics@ framework. The present studied cases show that a significant diffusion and redistribution of the load is due to an increasing in the level of material anisotropy.

Keywords: cosserat continua, anisotropic media, relative rotation, composites/masonry, finite element method

\section{INTRODUCTION}

A material can be defined complex due to the presence of an internal structure and to its complex constitutive behavior. As well-known, in the description of complex materials, such as composites, the discrete, and heterogeneous nature of matter must be taken into account, because interfaces and material internal phases dominate the gross behavior. The presence of material internal structure can be accounted by direct discrete modeling, with generally high computational cost (Suzuki et al., 1991; Baggio and Trovalusci, 2000; Rapaport and Rapaport, 2004; Yang et al., 2010; Godio et al., 2017; Baraldi et al., 2018; Reccia et al., 2018) or by adopting multiscale or coarse-graining techniques for deriving homogenized continua (Budiansky, 1965; Sanchez-Palencia, 1987; Nemat-Nasser et al., 1996; Blanc et al., 2002; Curtin and Miller, 2003; Jain and Ghosh, 2009; Trovalusci and Ostoja-Starzewski, 2011; Nguyen et al., 2012; Sadowski et al., 2014; Altenbach and Sadowski, 2015; Greco et al., 2016. However, the classical Cauchy model (Grade 1) is not reliable in the presence 
of problems dominated by the microstructure size, both in the non-linear, such as in the case of strain localization phenomena, and linear regimes (de Borst, 1991; Sluys et al., 1993; Masiani and Trovalusci, 1996; Trovalusci and Masiani, 1999, 2003).

In the framework of a multiscale modeling aimed at deriving homogenized continua suitable for representing the material microstructure, avoiding physical inadequacies and theoretical/computational problems-such as: ill-conditioning in the field equations and mesh-dependency in numerical solutions-the "non-local" character of the description is crucial. Non-locality, by definition, implies the presence of internal lengths and spatial dispersion properties in wave propagation (Kunin, 1982), which allow to bypass the above mentioned drawbacks. Besides the so-called explicit/strong nonlocal theories (Eringen, 1972, 1999; Maugin, 1993), implicit/weak non-local formulations, referred to continua with extra degrees of freedom of various kind (Mindlin, 1964; Capriz, 1989; Eringen, 1999; Gurtin, 2000; Trovalusci, 2014), have been proposed in order to deal with problems in which a characteristic internal length, $l$ (material length), is comparable to the macroscopic length, $L$ (structural length). This continua, also named multifield continua, reveal the hidden microstructure, which affects the macroscopic mechanical properties, by means of the additional kinematic and work-conjugated dynamic descriptors (Trovalusci and Augusti, 1998; Forest, 2009; Trovalusci et al., 2010; Capecchi et al., 2011; Forest and Trinh, 2011; Trovalusci, 2014; Trovalusci and Pau, 2014). In particular, in the works (Trovalusci and Augusti, 1998; Trovalusci et al., 2010; Trovalusci, 2014) the presence of a microstructure made of different kind of inclusions (fibers, microcracks/pores) and the ability of multifield continua to represent dispersion phenomena with particular reference to microcraked bars under free and forced oscillations has been investigated.

Among this latter kind of non-local models, many papers showed the advantages of micropolar models (e.g., formulated in Nowacki, 1970; Stojanović, 1972; Eringen, 1999, and widely investigated also from the experimental point of view Lakes and Benedict, 1982; Yang and Lakes, 1982; Lakes, 1983, 1986; Bauer et al., 2012; Rueger and Lakes, 2016) for investigating problems with general heterogeneities and/or discontinuities within the context of multiscale/coarsegraining approaches, which allow to preserve memory of the original organization of materials with periodic or random microstructure (Forest and Sab, 1998; Forest et al., 1999; Stefanou et al., 2008; Trovalusci et al., 2015, 2017). Moreover, special attention to the micropolar continua with constrained rotations (Toupin, 1962; Sokolowski, 1972), always referring to multiscale descriptions (Bouyge et al., 2001; Leonetti et al., 2018) has been reserved. In particular, the micropolar modeling has been effectively adopted for solving problems wherein the solid is made of an assembly of rigid particles undergoing displacements and rotations and interacting with each other via forces and couples, as masonry-like materials or fiber-reinforced composites, both in the linear and non-linear frameworks (Masiani and Trovalusci, 1996; Trovalusci and Masiani, 1999; Sansalone et al., 2006; Pau and Trovalusci, 2012; Trovalusci and Pau, 2014).
In the present work, we want to focus on the behavior of anisotropic composite assemblies, that can be polycrystals with grain boundaries or thin interfaces as well as brick/block masonry, and in particular on material parameters with different degrees of anisotropy. To this regard, it is worth noting that the micropolar continuum, differently from the couple-stress continuum, that is a micropolar continuum with constrained rotations (Sokolowski, 1972; Masiani and Trovalusci, 1996 Appendix), and also from second gradient continuum (Bacigalupo and Gambarotta, 2011; Trovalusci and Pau, 2014), presents the peculiar strain measure of the relative rotation between the local rigid rotation (macrorotation) and the microrotation that is related to the skew symmetric part of strain and then, in terms of work expended, to the skew symmetric part of the stress, whose contribution has significant role in anisotropic media (Pau and Trovalusci, 2012; Trovalusci and Pau, 2014). It is worth noting that, the different behavior between micropolar without and with constrained rotations media, for which the relative rotation is null, is also of interest for investigating the loss of ellipticity of problems leading to strain localization phenomena (Bigoni and Gourgiotis, 2016; Gourgiotis and Bigoni, 2016). Such effects are expected to be governed by both material size (de Borst, 1991; Sluys et al., 1993) and also the degree of anisotropy.

In a recent work (Leonetti et al., 2019), by adopting the coarse-graining procedure presented in Masiani and Trovalusci (1996); Trovalusci and Masiani (1999), the behavior of orthotropic brick/block masonry panels under compressive loads at the top, described as equivalent micropolar continua, has been investigated by varying the brick size and the load footprint, showing the capability of the micropolar model to distribute the load depending on the brick size. In the present work, the effect of the degree of anisotropy of the (coarse) continuum micropolar model on the strain/stress diffusion is studied. The same coarse-graining procedure is used which can be shown to be actually dependent both on the brick size, shape and texture of the original (fine) lattice model. The simulations have been carried out for a panel under localized loads, using a standard finite element approach based on a micropolar finite element implementation, with quadratic and linear interpolation functions for the displacement and rotation fields, developed in Fantuzzi et al. (2018) following the approach in Providas and Kattis (2002) and implemented within Comsol Multiphysics $\odot$ framework (Comsol, 2017). The results are presented in terms of contour plots of displacement, stress and relative rotation, the significant strain measure related to the non-symmetrical part of the strain.

The present work is structured as follows. After the introductory section, the mechanics of anisotropic micropolar continua is illustrated with particular emphasis on anisotropic composite assemblies in section Mechanics of Anisotropic Micropolar Continuum. Section Finite Element Formulation is dedicated to the finite element implementation. Section Numerical Simulations presents the numerical applications and discussions about the novel results presented in this work. Finally some conclusions and remarks are given. 


\section{MECHANICS OF ANISOTROPIC MICROPOLAR CONTINUUM}

The micropolar continuum is a well-known model equipped by theoretical, numerical, and experimental studies in the literature (Nowacki, 1970; Stojanović, 1972; Lakes and Benedict, 1982; Yang and Lakes, 1982; Lakes, 1983, 1986; Bauer et al., 2012; Rueger and Lakes, 2016). This continuum is made of particles which can undergo independent displacements and rotations and belongs to a class of generalized continua of the so-called implicit non-local type (Eringen, 1999; Trovalusci, 2014). Reducing the description to two-dimensional (2D) media, each material particle in the 2D frame has 3 degrees of freedom: the (macro) displacements components, $u_{1}, u_{2}$, and rotation, $\phi$ (micro-rotation). The local linearized kinematic compatibility relations take the form:

$$
\begin{aligned}
& \varepsilon_{11}=u_{1,1}, \quad \varepsilon_{22}=u_{2,2}, \quad \varepsilon_{12}=u_{1,2}+\phi, \\
& \varepsilon_{21}=u_{2,1}-\phi, \chi_{31}=\phi_{, 1}, \quad \chi_{32}=\phi_{, 2},
\end{aligned}
$$

where $\varepsilon_{i j}(i, j=1,2)$ indicate the components of the strain tensor, while $\chi_{31}, \chi_{32}$ indicate the only independent components of the curvature tensor. The term $\theta=\left(u_{2,1}-u_{1,2}\right) / 2$ is the local rigid rotation (macro-rotation) in such a way that:

$$
\varepsilon_{12}=u_{1,2}-\theta+\phi, \quad \varepsilon_{21}=u_{2,1}+\theta-\phi
$$

Interaction among particles is described by stresses and microcouples as:

$$
t_{i}=\sigma_{i j} n_{j}, m_{3}=\mu_{3 j} n_{j}
$$

where $\sigma_{i j}$ and $\mu_{i j}(i, j=1,2)$ are the components of the non-symmetric stress and couple-stress tensors, respectively, $n_{j}$ being the components of the outward normal to the continuum boundary. Equilibrium equations can be carried out, in the case of body micro-couple neglected, as:

$$
\sigma_{i j, j}+b_{i}=0, \mu_{3 j, j}-e_{i j 3} \sigma_{i j}=0,
$$

$b_{i}$ being the components of the body force.

Linearly anisotropic stress-strain relations of the micropolar two-dimensional continuum assume the following matrix form:

$$
\left[\begin{array}{l}
\sigma_{11} \\
\sigma_{22} \\
\sigma_{12} \\
\sigma_{21} \\
\mu_{31} \\
\mu_{32}
\end{array}\right]=\left[\begin{array}{llllll}
A_{1111} & A_{1122} & A_{1112} & A_{1121} & B_{111} & B_{112} \\
A_{2211} & A_{2222} & A_{2212} & A_{2221} & B_{221} & B_{222} \\
A_{1211} & A_{122} & A_{1212} & A_{1221} & B_{121} & B_{122} \\
A_{2111} & A_{2122} & A_{211} & A_{2121} & B_{211} & B_{212} \\
B_{111} & B_{122} & B_{112} & B_{121} & D_{11} & D_{12} \\
B_{211} & B_{222} & B_{212} & B_{221} & D_{21} & D_{22}
\end{array}\right]\left[\begin{array}{l}
\varepsilon_{11} \\
\varepsilon_{22} \\
\varepsilon_{12} \\
\varepsilon_{21} \\
\chi_{31} \\
\chi_{32}
\end{array}\right] .
$$

By considering hyperelastic materials, the following major symmetries hold: $A_{i j h k}=A_{h k i j}, B_{i j h}=B_{h i j}, D_{i j}=D_{j i}(i, j, h, k=1,2)$.

\section{FINITE ELEMENT FORMULATION}

The two-dimensional problem of micropolar continua is solved through the finite element implementation proposed in Leonetti et al. (2019), where displacement/rotation components are ordered in the vectors $\boldsymbol{u}=\left[\begin{array}{ll}u_{1} & u_{2}\end{array}\right]^{T}, \boldsymbol{\phi}=[\phi]$, and the stress and strain components in the vectors $\sigma=\left[\begin{array}{llll}\sigma_{11} & \sigma_{22} & \sigma_{12} & \sigma_{21}\end{array}\right]^{T}$, $\boldsymbol{\mu}=\left[\begin{array}{ll}\mu_{31} & \mu_{32}\end{array}\right]^{T}, \boldsymbol{\varepsilon}=\left[\begin{array}{llll}\varepsilon_{11} & \varepsilon_{22} & \varepsilon_{12} & \varepsilon_{21}\end{array}\right]^{T}, \boldsymbol{\chi}=\left[\begin{array}{ll}\chi_{31} & \chi_{32}\end{array}\right]^{T}$.
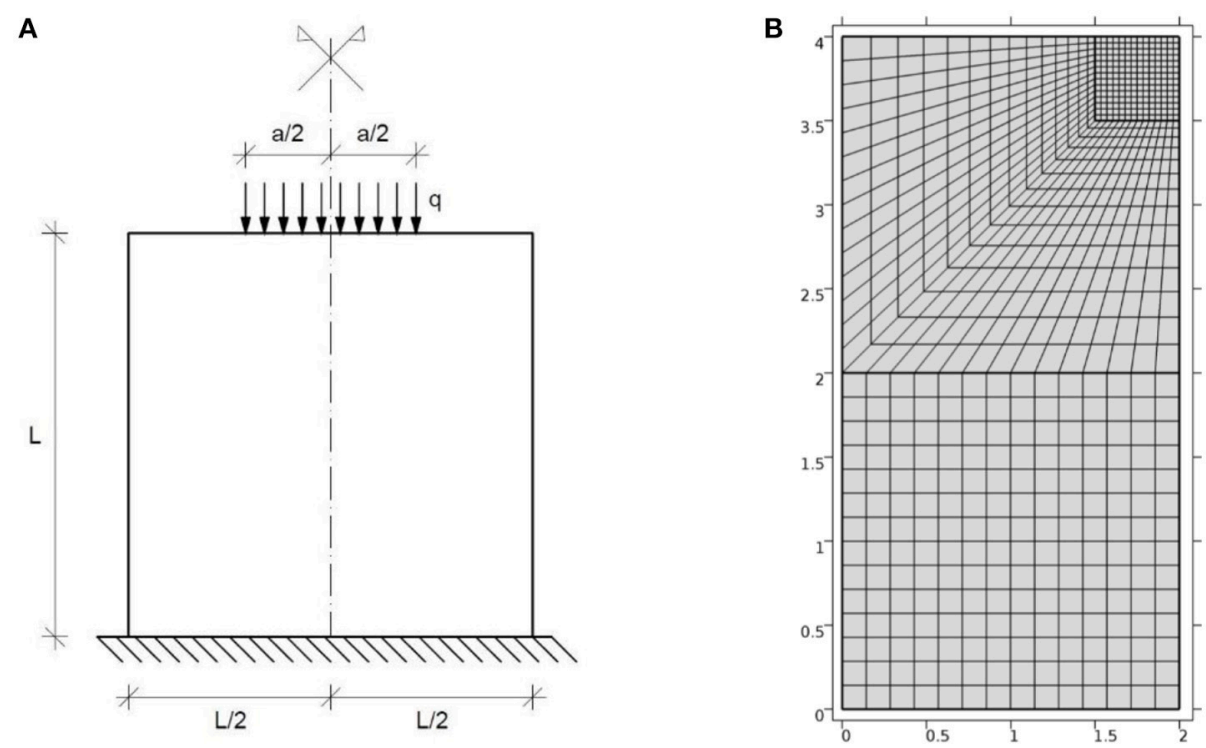

FIGURE 1 | (A) Sketch of the present problem with (B) present finite element mesh. 
The weak form of the present problem has to be formulated in order to carry out the finite element implementation, and, considering a domain $\Omega$ with boundary $\Gamma_{N}$, writes:

$$
\begin{array}{r}
\int_{\Omega} \delta \boldsymbol{\varepsilon}^{T} \boldsymbol{\sigma} d A+\int_{\Omega} \delta \boldsymbol{\chi}^{T} \boldsymbol{\mu} d A=\int_{\Omega} \delta \boldsymbol{u}^{T} \mathbf{b} d A+\int_{\Gamma_{N}} \delta \boldsymbol{u}^{T} \overline{\boldsymbol{t}} d l+ \\
\int_{\Gamma_{N}} \delta \boldsymbol{\phi}^{T} \overline{\boldsymbol{m}} d l \quad \forall \delta \boldsymbol{u}, \delta \boldsymbol{\phi},
\end{array}
$$

with $\delta$ denoting the variation operator, $\boldsymbol{b}$ the body force vector, $\overline{\boldsymbol{t}}$ and $\overline{\boldsymbol{m}}$ the traction and couple-traction vectors applied on the boundary $\boldsymbol{\Gamma}_{N}$. Note that, the curvature vector $\chi$ is due to the first-order partial derivatives of the micro-rotation, thus $C^{0}$ finite elements are adopted.

Finite element approximation though interpolation functions $\boldsymbol{N}_{u}$ and $\boldsymbol{N}_{\phi}$ is given by $\boldsymbol{u}=\boldsymbol{N}_{u} \tilde{\boldsymbol{u}}, \boldsymbol{\phi}=\boldsymbol{N}_{\phi} \tilde{\boldsymbol{\phi}}$, where the over tilde vectors indicate the kinematic parameters correspondent to in-plane displacements and rotations at the nodes. Quadratic interpolation functions for the displacements and linear ones for the rotations have been assumed, as it was introduced in Leonetti et al. (2019). Thus, displacements are modeled with nine nodes, whereas micro-rotation are related to the four corner nodes.

TABLE 1 | Constant mechanical properties used in all computations.

\begin{tabular}{ll}
\hline$A_{1111}$ & $3.75 \cdot 10^{4} \mathrm{MPa}$ \\
$A_{2222}$ & $1.5 \cdot 10^{4} \mathrm{MPa}$ \\
$A_{1212}$ & $0.75 \cdot 10^{4} \mathrm{MPa}$ \\
$A_{2121}$ & $3 \cdot 10^{4} \mathrm{MPa}$ \\
$D_{11}$ & $1.125 \cdot \mathrm{MN}$ \\
$D_{22}$ & $0.375 \cdot \mathrm{MN}$ \\
\hline
\end{tabular}

TABLE 2 | Mechanical properties used in Configuration 1.

\begin{tabular}{lcccc}
\hline & Material\#1 & Material\#2 & Material\#3 & Material\#4 \\
\hline$A_{1121}$ & $10^{4} \mathrm{MPa}$ & $1.5 \cdot 10^{4} \mathrm{MPa}$ & $2 \cdot 10^{4} \mathrm{MPa}$ & $2.5 \cdot 10^{4} \mathrm{MPa}$ \\
$A_{2212}$ & $0.25 \cdot 10^{4} \mathrm{MPa}$ & $0.375 \cdot 10^{4} \mathrm{MPa}$ & $0.5 \cdot 10^{4} \mathrm{MPa}$ & $0.625 \cdot 10^{4} \mathrm{MPa}$ \\
\hline
\end{tabular}

TABLE 3 | Mechanical properties used in Configuration 2.

\begin{tabular}{lcccc}
\hline & Material\#1 & Material\#2 & Material\#3 & Material\#4 \\
\hline$A_{1122}$ & $0 \mathrm{MPa}$ & $0.5 \cdot 10^{4} \mathrm{MPa}$ & $10^{4} \mathrm{MPa}$ & $1.5 \cdot 10^{4} \mathrm{MPa}$ \\
$D_{12}$ & $0 \mathrm{MN}$ & $0.5 \mathrm{MN}$ & $1 \mathrm{MN}$ & $1.5 \mathrm{MN}$ \\
\hline
\end{tabular}

TABLE 4 | Mechanical properties used in Configuration 3.

\begin{tabular}{ccccc}
\hline & Material\#1 & Material\#2 & Material\#3 & Material\#4 \\
\hline$A_{1112}$ & $0.25 \cdot 10^{4} \mathrm{MPa}$ & $0.30 \cdot 10^{4} \mathrm{MPa}$ & $0.35 \cdot 10^{4} \mathrm{MPa}$ & $0.40 \cdot 10^{4} \mathrm{MPa}$ \\
$A_{2221}$ & $10^{4} \mathrm{MPa}$ & $1.2 \cdot 10^{4} \mathrm{MPa}$ & $1.4 \cdot 10^{4} \mathrm{MPa}$ & $1.6 \cdot 10^{4} \mathrm{MPa}$
\end{tabular}

Interpolation function vectors are given in matrix form as:

$$
\boldsymbol{N}_{u}=\left[\begin{array}{ccccc}
N_{1}^{u} & 0 & \ldots & N_{9}^{u} & 0 \\
0 & N_{1}^{u} & & 0 & N_{9}^{u}
\end{array}\right], \boldsymbol{N}_{\phi}=\left[\begin{array}{ccc}
N_{1}^{\phi} & \cdots & N_{4}^{\phi}
\end{array}\right],
$$

Thus, the micropolar strains given by Equation (1) can be written as:

$$
\varepsilon=L u+M \phi, \chi=\nabla \phi
$$

where the matrix operators $\boldsymbol{L}$ and $\boldsymbol{M}$ are defined as:

$$
\boldsymbol{L}=\left[\begin{array}{cccc}
\frac{\partial}{\partial x_{1}} & 0 & \frac{\partial}{\partial x_{2}} & 0 \\
0 & \frac{\partial}{\partial x_{2}} & 0 & \frac{\partial}{\partial x_{1}}
\end{array}\right]^{T}, \boldsymbol{M}=\left[\begin{array}{llll}
0 & 0 & 1 & -1
\end{array}\right]^{T}
$$

Then Equation (8) becomes:

$$
\begin{aligned}
\boldsymbol{\varepsilon}= & \boldsymbol{L} \boldsymbol{N}_{u} \tilde{\boldsymbol{u}}+\boldsymbol{M N _ { \phi }} \tilde{\boldsymbol{\phi}}=\left[\begin{array}{ll}
L N_{u} & M N_{\phi}
\end{array}\right]\left\{\begin{array}{l}
\tilde{\boldsymbol{u}} \\
\tilde{\boldsymbol{\phi}}
\end{array}\right\}=\boldsymbol{B}_{\varepsilon} \boldsymbol{d}, \chi=\nabla\left(\boldsymbol{N}_{\phi} \tilde{\boldsymbol{\phi}}\right) \\
= & {\left[\begin{array}{ll}
\boldsymbol{0} & \nabla \boldsymbol{N}_{\phi}
\end{array}\right]\left\{\begin{array}{l}
\tilde{\boldsymbol{u}} \\
\tilde{\boldsymbol{\phi}}
\end{array}\right\}=\boldsymbol{B}_{\chi} \boldsymbol{d}, }
\end{aligned}
$$

Where $\boldsymbol{d}$ indicates the unknown vector of nodal displacements. The matrices $\boldsymbol{B}_{\varepsilon}$ and $\boldsymbol{B}_{\chi}$ collect the derivatives of the interpolation functions matrices $\boldsymbol{N}_{u}$ and $\boldsymbol{N}_{\phi}$. Therefore, the constitutive relations (5) become:

$$
\boldsymbol{\sigma}=\boldsymbol{D}_{\varepsilon \varepsilon} \boldsymbol{B}_{\varepsilon} \boldsymbol{d}+\boldsymbol{D}_{\varepsilon \chi} \boldsymbol{B}_{\chi} \boldsymbol{d}, \boldsymbol{\mu}=\boldsymbol{D}_{\varepsilon \chi}^{T} \boldsymbol{B}_{\varepsilon} \boldsymbol{d}+\boldsymbol{D}_{\chi \chi} \boldsymbol{B}_{\chi} \boldsymbol{d},
$$

where:

$$
\begin{aligned}
\boldsymbol{D}_{\varepsilon \varepsilon}= & {\left[\begin{array}{llll}
A_{1111} & A_{1122} & A_{1112} & A_{1121} \\
A_{2211} & A_{2222} & A_{2212} & A_{2221} \\
A_{1211} & A_{1222} & A_{1212} & A_{1221} \\
A_{2111} & A_{2122} & A_{2112} & A_{2121}
\end{array}\right], } \\
\boldsymbol{D}_{\varepsilon \chi}= & {\left[\begin{array}{ll}
B_{111} & B_{112} \\
B_{221} & B_{222} \\
B_{121} & B_{122} \\
B_{211} & B_{212}
\end{array}\right], \boldsymbol{D}_{\chi \chi}=\left[\begin{array}{ll}
D_{11} & D_{12} \\
D_{21} & D_{22}
\end{array}\right] . }
\end{aligned}
$$

Note that coupling between classical and micro-polar effects are considered by matrix $\boldsymbol{D}_{\varepsilon \chi}$. Finally, the algebraic finite element problem (without body forces) reads:

$$
\begin{aligned}
\delta \boldsymbol{d}^{T} & \underbrace{}_{\boldsymbol{K}} \underbrace{}_{\boldsymbol{\Omega}}\left(\boldsymbol{B}_{\varepsilon}^{T} \boldsymbol{D}_{\varepsilon \varepsilon} \boldsymbol{B}_{\varepsilon}+\boldsymbol{B}_{\varepsilon}^{T} \boldsymbol{D}_{\varepsilon \chi} \boldsymbol{B}_{\chi}+\boldsymbol{B}_{\chi}^{T} \boldsymbol{D}_{\varepsilon \chi}^{T} \boldsymbol{B}_{\varepsilon}+\boldsymbol{B}_{\chi}^{T} \boldsymbol{D}_{\chi \chi} \boldsymbol{B}_{\chi}\right) d A \boldsymbol{d} \\
& =\delta \boldsymbol{d}^{T} \underbrace{\int}_{\Gamma_{\Gamma_{\boldsymbol{N}}}\left[\begin{array}{c}
\boldsymbol{N}_{u}^{T} \overline{\boldsymbol{t}} \\
\boldsymbol{N}_{\phi}^{T} \overline{\boldsymbol{m}}
\end{array}\right]} \underbrace{\forall \delta \boldsymbol{d},}_{\boldsymbol{F}}
\end{aligned}
$$




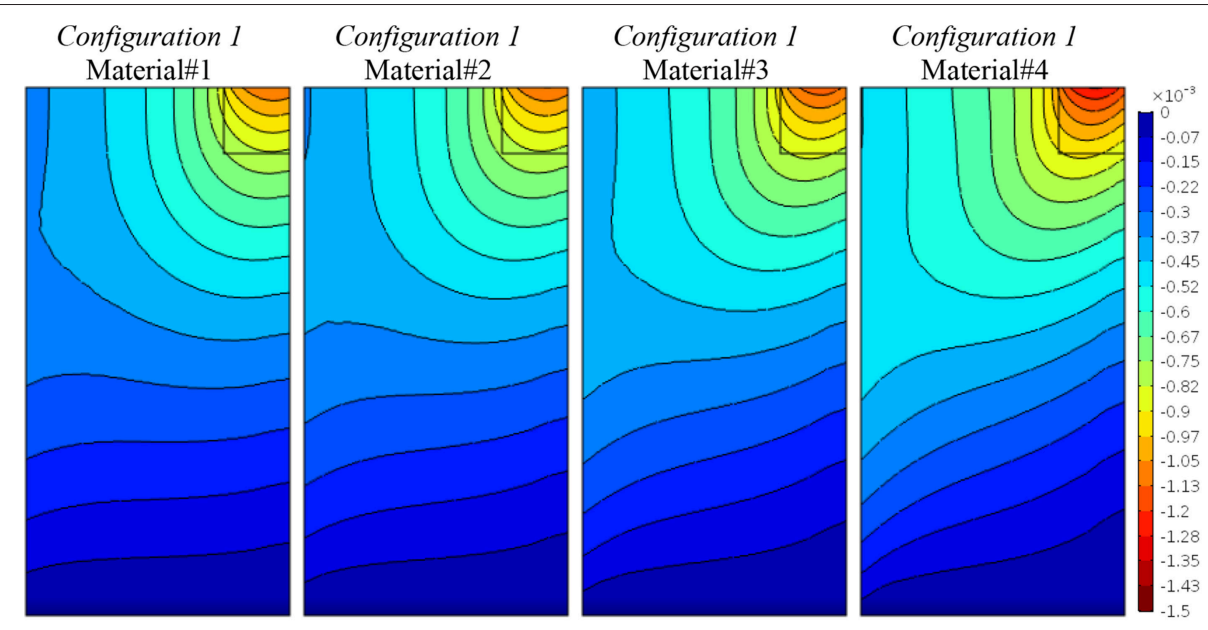

FIGURE 2 | Configuration 1, vertical displacement component, $u_{2}$, contour plots for four material cases (Material\#1/Material\#4 minimum/maximum anisotropy degree).
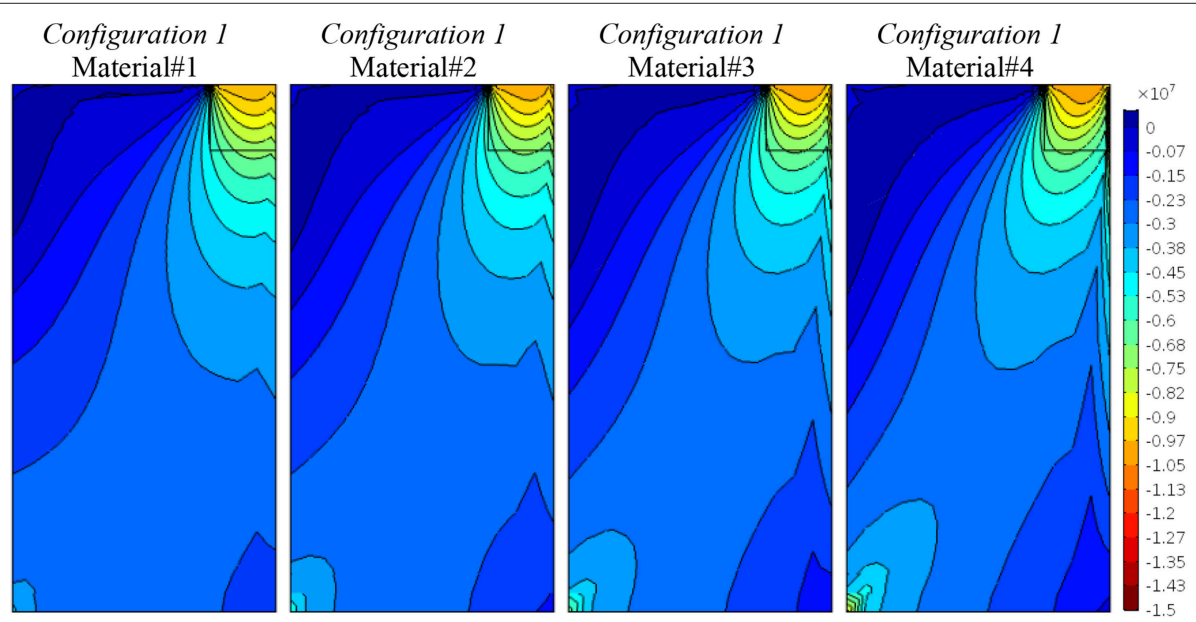

FIGURE 3 | Configuration 1, vertical stress component, $\sigma_{22}$, contour plots for four material cases (Material\#1/Material\#4 minimum/maximum anisotropy degree).

where $\boldsymbol{K}$ and $\boldsymbol{F}$ indicate the stiffness matrix and the nodal force vector of the adopted finite element for describing $2 \mathrm{D}$ linearly elastic anisotropic micropolar bodies. A classical GaussLegendre integration is considered for computing the integral terms appearing in Equation (13).

The present model has been implemented within the framework of Comsol Multiphysics ${ }^{\circledR}$ software (Comsol, 2017).

\section{NUMERICAL SIMULATIONS}

The present study aims at investigating the mechanical behavior of two-dimensional anisotropic micropolar media under localized loads by varying the degree of anisotropy, through the change in the material properties identified using the coarse-graining procedure described in Masiani and Trovalusci (1996), Trovalusci and Masiani (1999), considering at the (fine) micro-level anisotropic brick/block assemblies of different textures and related aspect and ratios, and at the macroscopic (coarse) level an energy equivalent micropolar continua.

It has been widely shown that homogenized micropolar models prove to be suitable of retaining memory of the behavior of the actual composite microstructure in the presence of high gradients of deformation, that occur even in the elastic range when load or geometrical singularities are present (Masiani and Trovalusci, 1996; Trovalusci and Masiani, 1999; Sansalone et al., 2006). In particular, due to the presence of the relative strain measure, it has been shown that micropolar continua perform better than classic and other generalized continua when nonsymmetric shear effects have to be accounted for, as in the case of strongly orthotropic media (Pau and Trovalusci, 2012; Trovalusci and Pau, 2014).

The role of scale effects in orthotropic media under the action of a load applied on portions of variable size of the boundary of the body and the consequences in terms of strain 


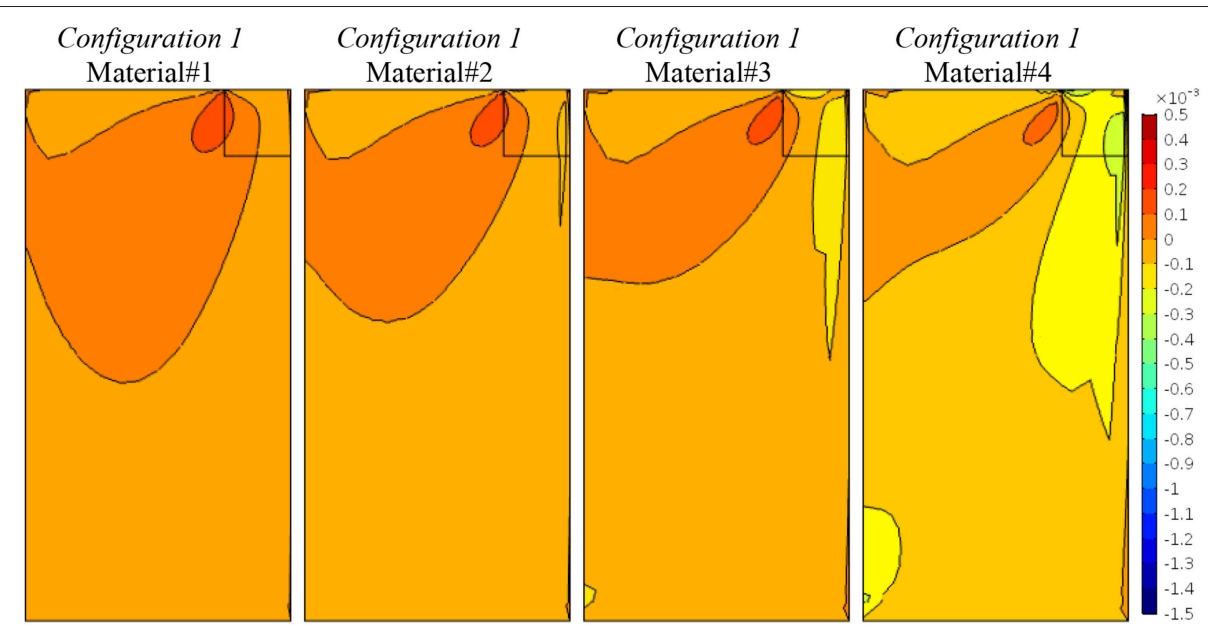

FIGURE 4 | Configuration 1, relative rotations, $\theta-\phi$, contour plots for four material cases (Material\#1/Material\#4 minimum/maximum anisotropy degree).
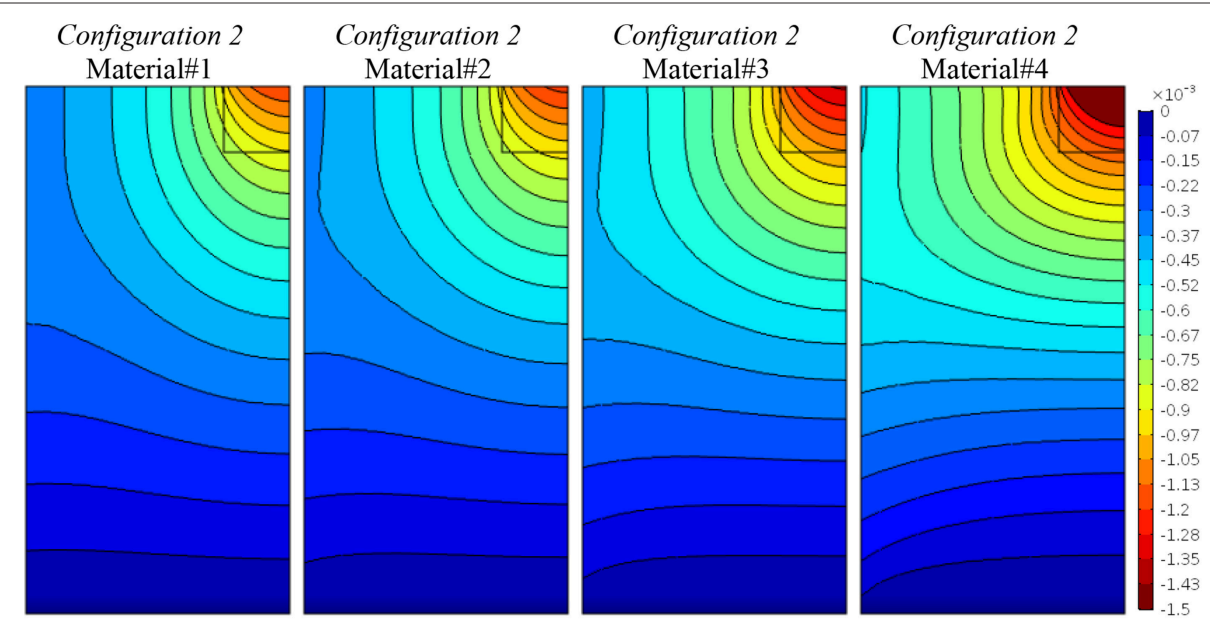

FIGURE 5 | Configuration 2, vertical displacement component, $u_{2}$, contour plots for four material cases (Material\#1/Material\#4 minimum/maximum anisotropy degree).

and stress diffusion have been highlighted by the parametric analyses performed in the recent work (Leonetti et al., 2019). The present work, does not accounts for size effects but focuses on the response of anisotropic micropolar media, under localized loads, in the presence of an increasing degree of anisotropy. The strain/stress diffusion has been numerically investigated according to the constitutive relations considered, that couple the effect of normal and shear stress/strain, as well as couple stress and curvature in orthogonal direction. This study highlights aspects that, in the Authors' knowledge, have not been previously investigated in materials with anisotropies. These aspects can be also interesting in the perspective of dealing with significant problems of loss of ellipticity followed by strain localization phenomena, with folding and/or fracture for instance, that affect both classical and constrained micropolar materials (Sluys et al., 1993; Nguyen et al., 2012; Bigoni and Gourgiotis, 2016; Gourgiotis and Bigoni, 2016).
The problem numerically investigated is a square domain of width $L=4 \mathrm{~m}$, only fixed at the bottom edge and subjected to a top load acting on length size $a / L=0.25$ (Figure 1A) and pressure $q=10 \mathrm{MPa}$. Due to the symmetry of the problem only half of the domain has been analyzed and the correspondent finite element mesh is depicted in Figure 1B. Parametric analyses have been performed by increasing the coefficients representing material anisotropy according to the following three different configurations that have been selected in order to investigate separately the role of different cases of anisotropy.

Table 1 reports the independent material coefficients that are considered constant in the simulations. The other coefficients increase according to a constant parameter allowing to represent four different degrees of anisotropy from a minimum (defined as Material \#1) to a maximum (Material \#4) value. 


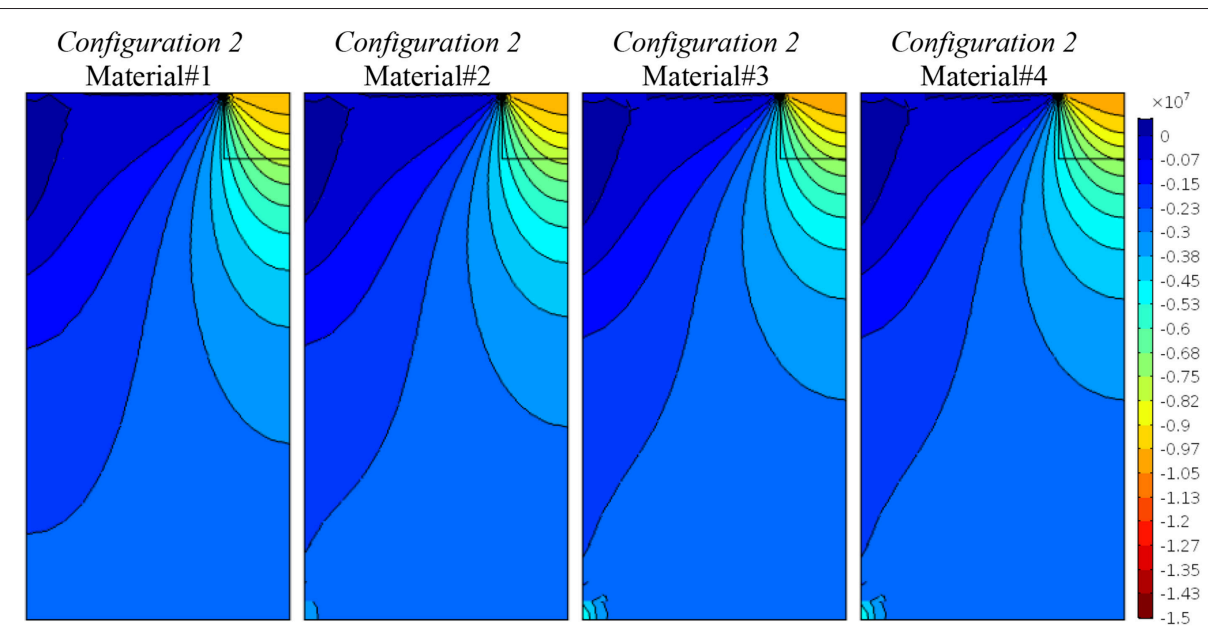

FIGURE 6 | Configuration 2, vertical stress component, $\sigma_{22}$, contour plots for four material cases (Material\#1/Material\#4 minimum/maximum anisotropy degree).
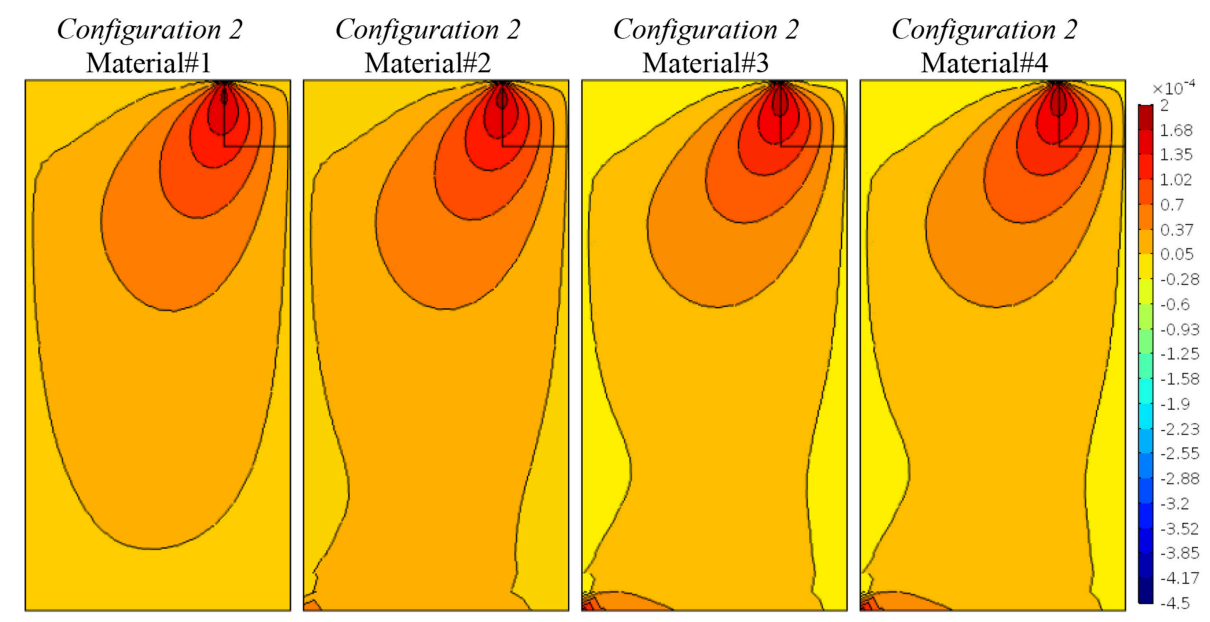

FIGURE 7 | Configuration 2, relative rotations, $\theta-\phi$, contour plots for four material cases (Material\#1/Material\#4 minimum/maximum anisotropy degree).

\section{Configuration 1:}

$$
\left[\begin{array}{l}
\sigma_{11} \\
\sigma_{22} \\
\sigma_{12} \\
\sigma_{21} \\
\mu_{31} \\
\mu_{32}
\end{array}\right]=\left[\begin{array}{llllll}
A_{1111} & \multicolumn{5}{c}{\boldsymbol{A}_{1121}} \\
& A_{2222} & \boldsymbol{A}_{2212} & & & \\
& \boldsymbol{A}_{1222} & A_{1212} & & & \\
\boldsymbol{A}_{2111} & & & A_{2121} & & \\
& & & & D_{11} & \\
& & & & & D_{22}
\end{array}\right]\left[\begin{array}{l}
\varepsilon_{11} \\
\varepsilon_{22} \\
\varepsilon_{12} \\
\varepsilon_{21} \\
\chi_{31} \\
\chi_{32}
\end{array}\right],
$$

accounts for the increment of the constitutive elastic coefficients (reported in bold in Equation (14)) coupling the normal stresses $\sigma_{11}, \sigma_{22}$ with the non-symmetric shear strains $\varepsilon_{21}, \varepsilon_{12}$, respectively, and the non-symmetric shear stresses $\sigma_{12}, \sigma_{21}$ with the normal strains $\varepsilon_{22}, \varepsilon_{11}$, respectively: $A_{1121}=A_{2111}$ and $A_{2212}=A_{1222}$. The implemented values are listed in Table 2 and their values for the four materials configurations considered (ranging from Material\#1, with the lower degree of anisotropy, up to Matrerial\#4 with the higher degree of anisotrpoy) are obtained by considering the increase through a parameter corresponding to $\left(A_{1212}-A_{2212}\right) / 4$ and $\left(A_{2121}-A_{1121}\right) / 4$, respectively. This choice is arbitrary, but it allows us to define an increasing degree of material anisotropy obtaining plausible results, as the elastic constants on the main diagonal are generally predominant with respect to the out-of-diagonal terms, suitable to highlight the effects of interest.

Configuration 2:

$$
\left[\begin{array}{l}
\sigma_{11} \\
\sigma_{22} \\
\sigma_{12} \\
\sigma_{21} \\
\mu_{31} \\
\mu_{32}
\end{array}\right]=\left[\begin{array}{llllll}
A_{1111} & \boldsymbol{A}_{1122} & & & & \\
\boldsymbol{A}_{2211} & A_{2222} & & & & \\
& & A_{1212} & & & \\
& & & A_{2121} & & \\
& & & & D_{11} & \boldsymbol{D}_{12} \\
& & & & \boldsymbol{D}_{21} & D_{22}
\end{array}\right]\left[\begin{array}{c}
\varepsilon_{11} \\
\varepsilon_{22} \\
\varepsilon_{12} \\
\varepsilon_{21} \\
\chi_{31} \\
\chi_{32}
\end{array}\right],
$$

considers a micropolar orthotropic material, where the variable elastic coefficients (reported in bold in Equation (15)) are: 


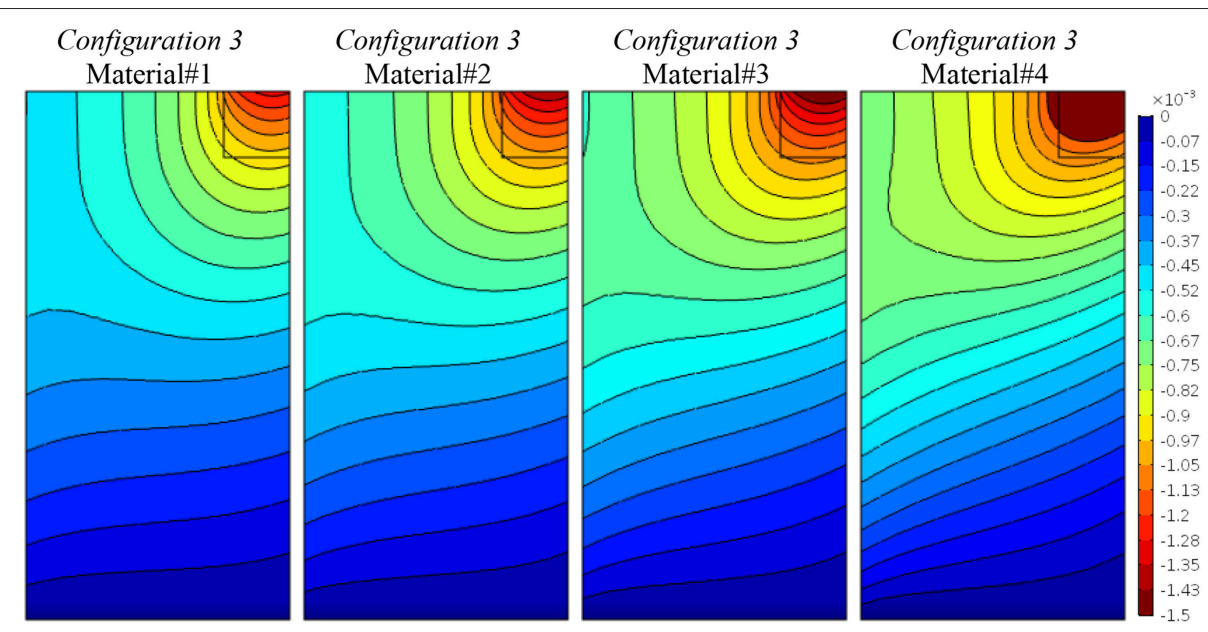

FIGURE 8 | Configuration 3, vertical displacement component, $u_{2}$, contour plots for four material cases (Material\#1/Material\#4 minimum/ maximum anisotropy degree).
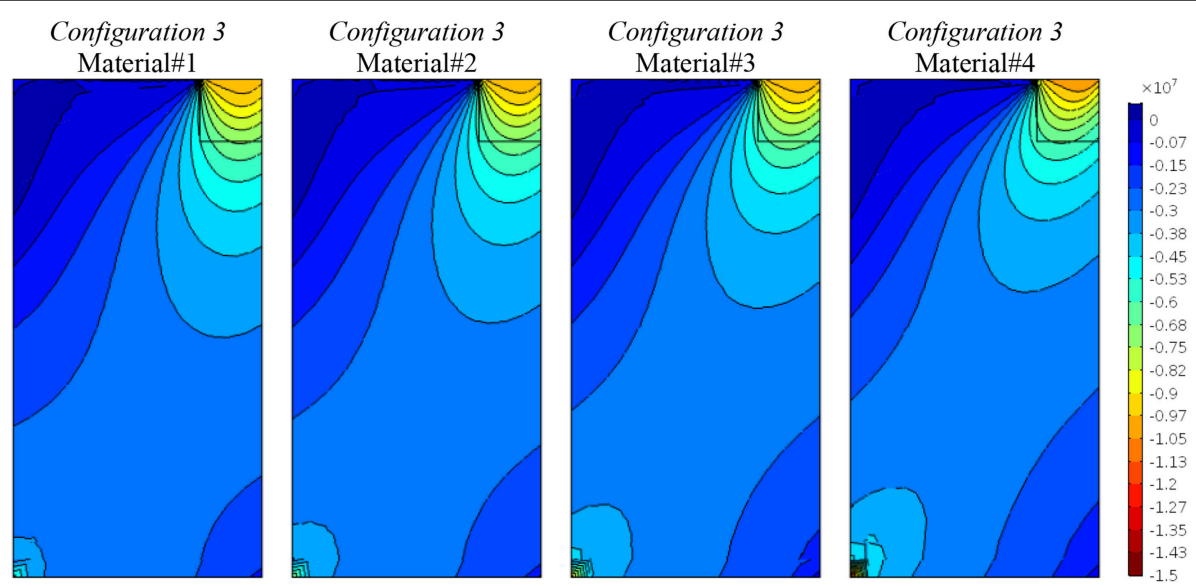

FIGURE 9 | Configuration 3, vertical stress component, $\sigma_{22}$, contour plots for four material cases (Material\#1/Material\#4 minimum/maximum anisotropy degree).

$A_{1122}=A_{2211}$ and $D_{12}=D_{21}$, respectively concerns the classical "Poisson effect" and a corresponding micropolar out-of-diagonal effect in the model. The values provided are listed in Table 3. Also in this case the increase from Material\#1 (with no Poisson's effect) to Material\#4 (with the higher Poisson's effect) has been put constant.

Configuration 3:

$$
\left[\begin{array}{l}
\sigma_{11} \\
\sigma_{22} \\
\sigma_{12} \\
\sigma_{21} \\
\mu_{31} \\
\mu_{32}
\end{array}\right]=\left[\begin{array}{llllll}
A_{1111} & & A_{1112} & & & \\
& A_{2222} & & A_{2221} & & \\
A_{1211} & & A_{1212} & & & \\
& A_{2122} & & A_{2121} & & \\
& & & & D_{11} & \\
& & & & & D_{22}
\end{array}\right]\left[\begin{array}{l}
\varepsilon_{11} \\
\varepsilon_{22} \\
\varepsilon_{12} \\
\varepsilon_{21} \\
\chi_{31} \\
\chi_{32}
\end{array}\right],
$$

takes into account the increment of the material coefficients (reported in bold in Equation (16)) that couple the normal stresses $\sigma_{11}, \sigma_{22}$ with the correspondent non-symmetric shear strains $\varepsilon_{12}, \varepsilon_{21}$, respectively, and the non-symmetric shear stresses $\sigma_{12}, \sigma_{21}$ with the normal strains $\varepsilon_{11}, \varepsilon_{22}$, respectively: $A_{1112}=A_{1211}$ and $A_{2221}=A_{2122}$. The implemented values are listed in Table 4, and their values for the four materials configurations considered are obtained by considering the increase of a parameter corresponding to $\left(A_{1212}-A_{1112}\right) / 10$ and $\left(A_{2121}-A_{2221}\right) / 10$, respectively. This arbitrary choice was due on the observed strongly coupling (normal/transversal) effects on the micropolar response. As for Configuaration 1, it allows us to define an increasing degree of material anisotropy obtaining results suitable to highlight the relevant effects.

Figures 2-4 represent the contour lines of the vertical component of displacement, $u_{2}$, the vertical stress component, $\sigma_{22}$, and relative rotation, $\theta-\phi$, for Configuration 1, in which the coupling material properties between normal stresses and the correspondent shear strains, and vice-versa, increase (Equation (14)) as above described. In terms of displacements (Figure 1) it can be observed that, due to the normal stress/shear strain/ coupling, the more the anisotropic degree, and the related 

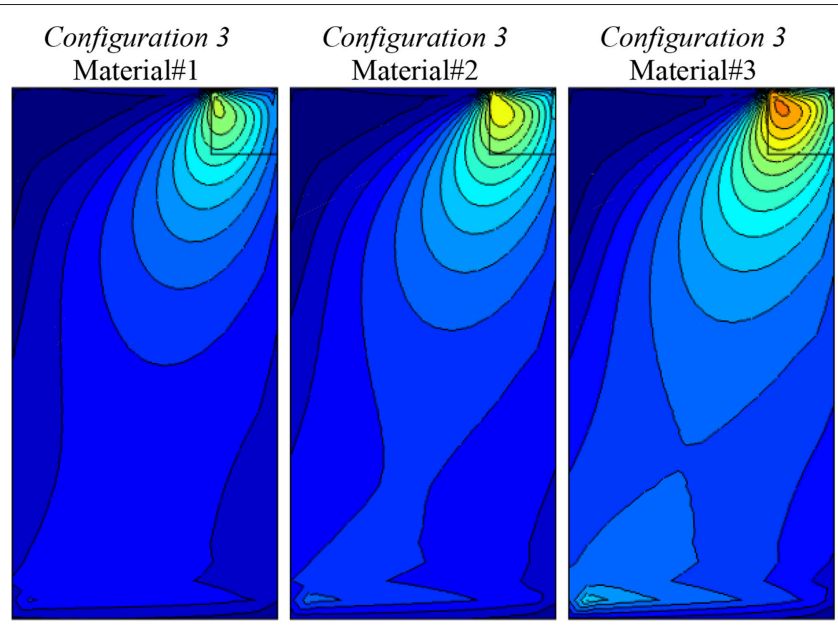

Configuration 3

Material\#4

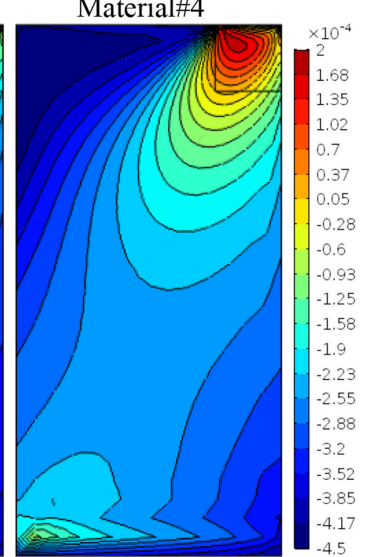

FIGURE 10 | Configuration 3, relative rotations, $\theta-\phi$, contour plots for four material cases (Material\#1/Material\#4 minimum/maximum anisotropy degree).

coupling, increases, from Material\#1 to Material\#4, the more the load distributes affecting the panel in its bottom part. Correspondingly, in terms of vertical stresses (Figure 3) the coupling due to anisotropy increases the stress diffusion. This effect is highlighted also by the relative rotation plot (Figure 4), wherein the micropolar effect of $\theta-\phi$ increases in Material $\# 4$ case due to the presence of a strongly anisotropy/coupling between normal and shear components.

Figures 5-7 show the results obtained for Configuration 2, characterized by the orthotropic material symmetry, which considers the classical and, in a sense, micropolar "Poisson's effect" through the terms $A_{1122}, D_{12}$. The first material case (Material\#1) corresponds to the one with null Poisson's effect $\left(A_{1122}=D_{12}=0\right)$, whereas the others have increasing coefficients through a constant value as shown in Table 3. In Figure 5 the contour lines of the vertical component of displacement field, $u_{2}$, diffuse depending on the degree of anisotropy. Analogously, for the vertical stress component, $\sigma_{22}$, in Figure 6 we can observe the same phenomenon. In both cases the curves are more distributed in the case of higher degrees of orthotropy. Figure 7 shows that the relative rotation, $\theta-\phi$, map does not change, as this component is not affected by the elastic coefficients involved. For pointing out the correspondences between classical and micropolar elastic moduli the reader may refer to the work [Trovalusci and Masiani (1999), section 4].

Finally, Figures 8-10 are related to Configuration 3, which couples normal and shear stress/strain components as described in Equation (16). The present condition influences more the solution as it can be seen in Figure 8, where the vertical displacement component, $u_{2}$, changes homogeneously showing a wider diffusion related to the increasing of the degree of anisotropy. The same can be said for the vertical stress in Figure 9, where the reaction stresses at the bottom increases as the coupling effect increases. The most interesting representation is due to the relative rotation (Figure 10) where a strong boundary effect is shown. The field becomes distorted at the top (where the vertical load is applied) and at the bottom (even though an homogenous boundary condition has been applied) as the coupling mechanical properties are increased. The contour plot distortion at the bottom is due to the strong discontinuity between a clamped horizontal boundary condition and a free one on the left vertical edge.

\section{FINAL REMARKS}

This work proposes a numerical finite element solution of an anisotropic micropolar panel subjected to a concentrated pressure on a small portion of the top boundary, and the effect on the mechanical behavior of this body has been investigated for particular cases of material anisotropy. The stress diffusion under concentrated load in masonry assemblies has been widely investigated also from the experimental point of view (Bigoni and Noselli, 2010). In earlier works it has been shown that while the micropolar model is able to distribute the load depending on the element size, the classical continuum lacking in material internal lengths does not entail such effect. Moreover, the micropolar model, differently from the couple stress (micropolar with microtation constrained to be equal to the local rigid rotation) and second gradient model, presents the peculiar strain measure of relative rotation suitable to take into account the nonsymmetries in strain and stress that are predominant in strongly anisotropic assemblies (Pau and Trovalusci, 2012; Trovalusci, 2014; Trovalusci and Pau, 2014).

In the present work, attention has been given to the effect of different degrees of material anisotropy, not only orthotropy, for micropolar bodies subjected to localized loads, particularly focusing on the strain measure of the relative rotation. It has been highlighted that the anisotropic elastic coefficients of the micropolar continuum, which couple normal stresses with non-symmetric shear strains and vice-versa, have the effect of distributing the load according to the degree of anisotropy of the reference material. The coefficients that relate normal stress to normal strain components in the orthogonal directions, as well as the coefficients relating the couple-stress to the curvature components in the orthogonal direction, governing the classical and, in a sense, micropolar Poisson's effect, instead, does not 
significantly affect the response of the micropolar continuum. All the analyzed cases showed that an increasing level of anisotropy corresponds to a significant distribution of the load in terms of stresses within the continuum.

It can be concluded that when dialing with materials made of particles assembled according to strong anisotropies it is advisable to resort to micropolar theories. As further development, we expect to investigate the ability of unconstrained anisotropic micropolar models to detect strain localization phenomena.

\section{AUTHOR CONTRIBUTIONS}

NF and PT wrote and revise the paper. SD carried out all numerical simulations.

\section{REFERENCES}

Altenbach, H., and Sadowski, T. (2015). Failure and Damage Analysis of Advanced Materials. Wien: Springer-Verlag.

Bacigalupo, A., and Gambarotta, L. (2011). Non-local computational homogenization of periodic masonry. Int. J. Multiscale. Comput. Eng. 9, 565-578. doi: 10.1615/IntJMultCompEng.2011002017

Baggio, C., and Trovalusci, P (2000). Collapse behaviour of three-dimensional brick-block systems using non linear programming. Struct. Eng. Mech. 10, 181-195. doi: 10.12989/sem.2000.10.2.181

Baraldi, D., Reccia, E., and Cecchi, A. (2018). In plane loaded masonry walls: DEM and FEM/DEM models. a critical review. Meccanica 53, 1613-1628. doi: 10.1007/s11012-017-0704-3

Bauer, S., Dettmer, W. G., Perić, D., and Schäfer, M. (2012). Micropolar hyperelasticity: constitutive model, consistent linearization and simulation of 3D scale effects. Comput. Mech. 50, 383-396. doi: 10.1007/s00466-012-0 679-9

Bigoni, D., Gourgiotis, P. A. (2016). Folding and faulting of an elastic continuum. Proc. Royal Soc. A. 472:20160018.

Bigoni, D., and Noselli, G. (2010). Localize stress percolation through dry masonry walls. Part I - Experiments. Eur. J. Mech A/Solids. 29, 291-298. doi: 10.1016/j.euromechsol.2009.10.009

Blanc, C., Le Bris, C., and Lions, P. L. (2002). From molecular models to continuum mechanics. Arch. Rat. Mech. Anal. 164, 341-381. doi: 10.1007/s00205-002-0218-5

Bouyge, F., Jasiuk, I., and Ostoja-Starzewski, M. (2001). Micromechanically based couple-stress model of an elastic two-phase composite. Int. J. Solids Struct. 38, 1721-1735. doi: 10.1016/S0020-7683(00)00132-3

Budiansky, B. (1965). On the elastic moduli of some heterogeneous materials. J. Mech. Phys. Solids 13, 223-227.

Capecchi, D., Ruta, G., and Trovalusci, P. (2011). Voigt and Poincarés mechanistic-energetic approaches to linear elasticity and suggestions for multiscale modelling. Arch. Appl. Mech. 81, 1573-1584. doi: 10.1007/s00419-010-0502-z

Capriz, G. (1989). Continua with Microstructure. Berlin: Springer-Verlag. doi: 10.1007/978-1-4612-3584-2

Comsol, A. B. (2017). Comsol Multiphysics Physics Builder Manual. Stockholm: Comsol.

Curtin, W. A., and Miller, R. E. (2003). Atomistic/continuum coupling in computational materials science. Model. Simul. Mater. Sci. Eng. 11, R33-R68. doi: 10.1088/0965-0393/11/3/201

de Borst, R. (1991). Simulation of strain localization: a reappraisal of the Cosserat continuum. Eng. Comput. 8, 317-332. doi: 10.1108/eb023842

Eringen, A. C. (1972). Linear theory of nonlocal elasticity and dispersion of plane waves. Int. J. Eng. Sci. 10, 425-435. doi: 10.1016/0020-7225(72)90050-X

Eringen, A. C. (1999). Microcontinuum Field Theories. New York, NY: SpringerVerlag. doi: 10.1007/978-1-4612-0555-5

\section{ACKNOWLEDGMENTS}

The authors acknowledge Dr. Lorenzo Leonetti, University of Calabria, for providing the Comsol ${ }^{\circledR}$ framework and for implementing the model at Section Finite Element Formulation for the present investigation.

\section{FUNDING}

This research was supported by the Italian Ministry of University and Research, P.R.I.N. 2015, Project 2015JW9NJT Advanced mechanical modeling of new materials and structures for the solution of 2020 Horizon challenges, Sapienza Research Unit (Grant B86J16002300001), and by Sapienza University, Grant 2016 (B82F16005920005).

Fantuzzi, N., Leonetti, L., Trovalusci, P., and Tornabene, F. (2018). Some novel numerical applications of Cosserat continua. Int. J. Comput. Meth. 15:1850054. doi: $10.1142 / S 0219876218500548$

Forest, S. (2009). Micromorphic approach for gradient elasticity, viscoplasticity, and damage. J. Eng. Mech. 135, 117-131. doi: 10.1061/(ASCE)0733-9399(2009)135:3(117)

Forest, S., Dendievel, R., and Canova, G. R. (1999). Estimating the overall properties of heterogeneous Cosserat materials. Model. Simul. Mater. Sci. Eng. 7, 829-840. doi: 10.1088/0965-0393/7/5/314

Forest, S., and Sab, K. (1998). Cosserat overall modeling of heterogeneous materials. Mech. Res. Commun. 25, 449-454. doi: 10.1016/S0093-6413(98)00059-7

Forest, S., and Trinh, D. K. (2011). Generalised continua and the mechanics of heterogeneous material. Zeitschrift für Angewandte Mathematik und Mechanik 91, 90-109. doi: 10.1002/zamm.201000109

Godio, M., Stefanou, I., Sab, K., Sulem, J., and Sakji, S. (2017). A limit analysis approach based on Cosserat continuum for the evaluation of the in-plane strength of discrete media: application to masonry. Eur. J. Mech. A Solids. 66, 168-192. doi: 10.1016/j.euromechsol.2017.06.011

Gourgiotis, P. A., Bigoni, D. (2016). Stress channelling in extreme couple-stress materials Part I: Strong ellipticity, wave propagation, ellipticity, and discontinuity relations. J. Mech. Phys. Solids. 88, 150-168. doi: 10.1016/j.jmps.2015.09.006

Greco, F., Leonetti, L., Luciano, R., and Nevone Blasi, P. (2016). Effects of microfracture and contact induced instabilities on the macroscopic response of finitely deformed elastic composites. Compos. Part B. Eng. 107, 233-253. doi: 10.1016/j.compositesb.2016.09.042

Gurtin, M. E. (2000). Configurational Forces as Basis Concept of Continuum Physics. Berlin: Springer-Verlag.

Jain, J. R., and Ghosh, S. (2009). Damage evolution in composites with a homogenization-based continuum damage mechanics model. Int. J. Damage Mech. 18, 533-568. doi: 10.1177/1056789508091563

Kunin, I. A. (1982). Elastic Media with Microstructure, I-II. Berlin: Springer-Verlag.

Lakes, R. S. (1983). Size effect and micromechanics of a porous solid. J. Mat. Sci. $18,2572-2580$.

Lakes, R. S. (1986). Experimental microelasticity of two porous solids. Int. J. Solids. Struct. 22, 55-63. doi: 10.1016/0020-7683(86)90103-4

Lakes, R. S., and Benedict, R. L. (1982). Noncentrosymmetry in micropolar elasticity. Int. J. Eng. Sci. 20, 1161-1167. doi: 10.1016/0020-7225(82)90096-9

Leonetti, L., Fantuzzi, N., Trovalusci, P., and Tornabene, F. (2019). Scale effects in orthotropic composite assemblies as micropolar continua: a comparison between weak and strong-form finite element solutions. Materials 12:758. doi: 10.3390/ma12050758

Leonetti, L., Greco, F., Trovalusci, P., Luciano, R., and Masiani, R. (2018). A multiscale damage analysis of periodic composites using a couplestress/Cauchy multidomain model: application to masonry structures. Compos. Part B. Eng. 141, 50-59. doi: 10.1016/j.compositesb.2017.12.025 
Masiani, R., and Trovalusci, P. (1996). Cosserat and cauchy materials as continuum models of brick masonry. Meccanica 31, 421-432. doi: 10.1007/BF00429930

Maugin, G. (1993). Material Inhomogeneities in Elasticity. London: Chapman and Hall. doi: 10.1007/978-1-4899-4481-8

Mindlin, R. D. (1964). Micro-structure in linear elasticity. Arch. Ration Mech. Anal. 16, 51-78. doi: 10.1007/BF00248490

Nemat-Nasser, S., Hori, M., and Datta, S. K. (1996). Micromechanics: overall properties of heterogeneous materials. J. Appl. Mech. 63:561. doi: $10.1115 / 1.2788912$

Nguyen, V. P., Lloberas-Valls, O., Stroeven, M., and Sluys, LJ. (2012). Computational homogenization for multiscale crack modelling, Implementational and computational aspects. Int. J. Numer. Meth. Engng. 89, 192-226. doi: 10.1002/nme.3237

Nowacki, W. (1970). Theory of Micropolar Elasticity. Udine: Springer-Verlag. doi: 10.1007/978-3-7091-2720-9

Pau, A., and Trovalusci, P. (2012). Block masonry as equivalent micropolar continua: the role of relative rotations. Acta Mech. 223, 1455-1471. doi: 10.1007/s00707-012-0662-8

Providas, E., and Kattis, M. A. (2002). Finite element method in plane Cosserat elasticity. Comput. Struct. 80, 2059-2069. doi: 10.1016/S0045-7949(02) 00262-6

Rapaport, D. C., and Rapaport, D. C. R. (2004). The Art of Molecular Dynamics Simulation. Cambridge, UK: Cambridge University Press.

Reccia, E., Leonetti, L., Trovalusci, P., and Cecchi, A (2018). A multiscale/multidomain model for the failure analysis of masonry walls: a validation with a combined FEM/DEM approach. Int. J. Mult. Comp. Eng. 16, 325-343. doi: 10.1615/IntJMultCompEng.2018026988

Rueger, Z., and Lakes, R. S. (2016). Cosserat elasticity of negative Poisson's ratio foam: experiment. Smart Mater. Struct. 25:054004. doi: 10.1088/0964-1726/25/5/054004

Sadowski, T., Trovalusci, P., Schrefler, B., de Borst, R. (2014). Multi-scale and multi-physics modelling for complex materials. Meccanica 49, 2549-2550. doi: 10.1007/s11012-014-0040-9

Sanchez-Palencia, E, and Zaoui, A. (1987). Homogenization Techniques For Composite Media. Lecture Notes In Physics. Springer.

Sansalone, V., Trovalusci, P., and Cleri, F. (2006). Multiscale modelling of materials by a multifield approach: microscopic stress and strain distribution in fiber-matrix composites. Acta Mater. 54, 3485-3492. doi: 10.1016/j.actamat.2006.03.041

Sluys, L. J., de Borst, R., and Mühlhaus, H. B. (1993). Wave propagation, localization and dispersion in a gradient-dependent medium. Int. J. Solid. Struct. 30, 1153-1171. doi: 10.1016/0020-7683(93)9 0010-5

Sokolowski, M (1972). Theory of Couple-stresses in Bodies with Constrained Rotations, Udine: Springer-Verlag.

Stefanou, I., Sulem, J., and Vardoulakis, I. (2008). Three-dimensional cosserat homogenization of masonry structures: elasticity. Acta Geotech. 3, 71-83. doi: 10.1007/s11440-007-0051-y

Stojanović, B. (1972). Recent Developments in the Continua of Polar Elasticity. Udine: Springer-Verlag.
Suzuki, T., Takeuchi, S., and Yoshinaga, H. (1991). Dislocation Dynamics and Plasticity. Berlin: Springer-Verlag.

Toupin, R. A. (1962). Elastic materials with couple-stresses. Arch Ration. Mech. Anal. 11, 385-414. doi: 10.1007/BF00253945

Trovalusci, P. (2014). "Molecular approaches for multifield continua: origins and current developments," in Multiscale Modeling of Complex Materials: Phenomenological, Theoretical and Computational Aspects, eds T. Sadowski, P. Trovalusci. (Berlin: Springer Int Centre for Mechanical Sciences), 211-278.

Trovalusci, P., and Augusti, G. (1998). A continuum model with microstructure for materials with flaws and inclusions. J. Phys. IV. 8, 383-390.

Trovalusci, P., De Bellis, M. L., and Masiani, R. (2017). A multiscale description of particle composites: From lattice microstructures to micropolar continua. Comp. Part B Eng. 128, 164-173. doi: 10.1016/j.compositesb.2017.06.015

Trovalusci, P., and Masiani, R. (1999). Material symmetries of micropolar continua equivalent to lattices. Int. J. Solid Struct. 36, 2091-2108. doi: 10.1016/S0020-7683(98)00073-0

Trovalusci, P., and Masiani, R. (2003). Non-linear micropolar and classical continua for anisotropic discontinuous materials. Int. J. Solid. Struct. 40, 1281-1297. doi: 10.1016/S0020-7683(02)00584-X

Trovalusci, P., and Ostoja-Starzewski, M. (2011). Multiscale mechanical modelling of complex materials and engineering applications 2. Int. J. Mult. Comp. Eng. 9, 7-9. doi: 10.1615/IntJMultCompEng.2011002870

Trovalusci, P., Ostoja-Starzewski, M., De Bellis, M. L., and Murrali, A. (2015). Scale-dependent homogenization of random composites as micropolar continua. Eur. J. Mech A Solids. 49, 396-407. doi: 10.1016/j.euromechsol.2014.08.010

Trovalusci, P., and Pau, A. (2014). Derivation of microstructured continua from lattice systems via principle of virtual works: the case of masonry-like materials as micropolar, second gradient and classical continua. Acta Mech. 225, 157-177. doi: 10.1007/s00707-013-0936-9

Trovalusci, P., Varano, V., and Rega, G. (2010). A generalized continuum formulation for composite materials and wave propagation in a microcracked bar. J. Appl. Mech. 77:061002. doi: 10.1115/1.4001639

Yang, D., Sheng, Y., Ye, J., and Tan, Y. (2010). Discrete element modeling of the microbond test of fiber reinforced composite. Comput Mater Sci. 49, 253-259. doi: 10.1016/j.commatsci.2010.05.003

Yang, J. F. C., and Lakes, R. S. (1982). Experimental study of micropolar and couple stress elasticity in compact bone in bending. J. Biomechanics. 15, 91-98.

Conflict of Interest Statement: The authors declare that the research was conducted in the absence of any commercial or financial relationships that could be construed as a potential conflict of interest.

Copyright (c) 2019 Fantuzzi, Trovalusci and Dharasura. This is an open-access article distributed under the terms of the Creative Commons Attribution License (CC BY). The use, distribution or reproduction in other forums is permitted, provided the original author(s) and the copyright owner(s) are credited and that the original publication in this journal is cited, in accordance with accepted academic practice. No use, distribution or reproduction is permitted which does not comply with these terms. 